\title{
Dispelling Common Myths About ACM Awards and Honors
}

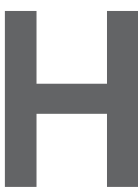
AVE YOU WONDERED why a person you admire has not received an ACM award, or been made a Distinguished Member or Fellow? We all want to see our colleagues recognized for their achievements. When an outstanding candidate has not received recognition, the reason is usually one of three things: they were not nominated at all, the nomination did not adequately address the committee's criteria, or this particular honor was not a good match for the candidate's background.

As a former ACM Awards Chair, I'd like to share some insights to help you understand what makes nominations effective. You will find similar-and additional-information on individual award Web pages, under "How to Nominate" and "Frequently Asked Questions."

Myth: The committee knows X's work already, so why hasn't she/he gotten the award? Reality: Even if the entire committee knows how great $\mathrm{X}$ is (which is probably a stretch, given that ACM committees must span such a broad range of expertise), that isn't enough. ACM requires a winner be chosen on the basis of the nomination packet that was submitted. If X was not formally nominated, or if the packet did not address the selection criteria, they cannot be selected.

Myth: I work with X, so I am the best person to nominate her/him. $R e^{-}$ ality: Nominations/endorsements are much stronger when they come from people outside the candidate's own organization. Not only can they speak to the broader impact of the work, they are also considered to be more objective since the writer won't derive any benefit if the candidate is successful. Why not help organize it instead by finding a nominator, providing background information, and perhaps helping to ensure the endorsements span a range of perspectives?

Myth: The more famous the nominator/endorsers are, the better. Reality: What the person says is more important than who the person is. It's also important to have endorsers address the selection criteria in different ways, rather than just reiterating the nominator's comments. That said, the same words will carry more weight when they are from a person with stature in the community, as opposed to someone who may not have as much experience to draw on.

Myth: Nominations from ACM Fellows are always successful, but I don't know any to ask. Reality: There's no requirement that a nominator/endorser be a Fellow or even an ACM member. It's often best to approach people who have cited or commented publicly on the quality of the candidate's work, even if you don't know them.

Myth: They never give this honor to people working outside North America. Reality: On the contrary, nothing makes our committees happier than to recognize achievements of people from around the globe. The sad truth is there are very few nominations from outside North America, and some of those suffer from the problems described in the other myths.

Myth: It was too competitive this year; we will just resubmit the same packet again next year. Reality: Think of it this way: leaving the packet unchanged implies the candidate didn't achieve anything new in the intervening year.

Myth: X does wonderful work, so let's go for the biggest award. Reality: The reason there are so many different awards/honors is that excellence occurs in different ways as one's career progresses. Choose a target that not only reflects the candidate's accomplishments, but also their career stage. There are few hard-and-fast rules, but the table here might be helpful to you.

Remember that ACM awards only exist because people like you identify and nominate outstanding individuals. For more details on specific awards and selection criteria, visit https:// awards.acm.org/award-nominations.c

Cherri M. Pancake is President of ACM, professor emeritus of electrical engineering and computer science, and director of a research center at Oregon State University, Corvallis, OR, USA.

Copyright held by author/owner.

\section{ACM offers a wide range of awards.}

\begin{tabular}{ll} 
Students & HPC Fellowships, Cutler-Bell Prize \\
\hline Early Career & $\begin{array}{l}\text { Hopper Award, ACM and SIG dissertation awards (recent graduates), } \\
\text { SIG "rising star" awards; also Senior Member }\end{array}$ \\
\hline Mid Career & ACM Prize; also Distinguished Member \\
\hline Late Career & Turing Award, Distinguished Service Award; also Fellow \\
\hline Area-Specific, typically & $\begin{array}{l}\text { Thacker Award, Software System Award, Athena Lecturer, Newell Award, } \\
\text { Mid to Late Career }\end{array}$ \\
& $\begin{array}{l}\text { Lawler Award, Eckert-Mauchly Award, Kennedy Award, Bell Prize, } \\
\text { Karlstrom Award, Kannellakis Award, Policy Award, SIAM/ACM Prize- } \\
\text { plus dozens of awards from individual SIGs }\end{array}$ \\
\hline
\end{tabular}

